\title{
Uma carta de seguro, em S. Paulo, concedida em 1872
}

\author{
J. Canuto Mendes de Almeida
}

1. A fiança é um meio coativo de garantir a participação do réu na instrução, preliminar ou definitiva, e na execução criminais. E' um meio de coação indireta, o que a distingue da prisão preventiva lato sensu e da condução debaixo de vara, que, embora destinadas ao mesmo fim de assegurar a presença do indiciado ou acusado aos principais atos processuais e o cumprimento da pena imposta, são meios de coação direta.

Outr'ora, entre nós, mais institutos existiram, ao lado da prisão e da fiança, com essa mesma finalidade de segurança do réu. Juristas e historiadores enumeram: a palavra de fieis carcereiros, a homenagem, o seguro.

2. As cartas de seguro, conforme se depreende dos dados históricos a elas relativos, constituiam uma proteção do rei a seus súbditos perante as justiças, para, mediante certas condições, os eximir da prisão processual. Foram uma garantia de liberdade, a princípio, sobretudo contra os abusos das justiças senhoriais, mas, usadas tambem perante os juizes dos conselhos, os tribunais eclesiásticos e as jurisdições reais, acabaram por divulgar-se como o meio mais simples de os réus se livrarem soltos. O Código de Processo Criminal, entretanto, aboliu, em 1832, "as cartas de seguro e qualquer outro meio que não seja o de fiança, para que algum réu se livre solto" (art. 113). 
3. Nossos arquivos oficiais possuem coleções de processos criminais da época colonial que encerram muitas cartas de seguro, concedidas, como era de lei, pelos corregedores das comarcas.

No século XVIII, os juizes ordinários, logo que lhes chegava a notícia de algum crime, abriam devassa, isto é, a formação da culpa preliminar, com corpo de delito e audiência secreta de testemunhas, geralmente em número de trinta, procedimento que se encerrava com a pronúncia. Lemos, na biblioteca do Arquivo do Estado de São Paulo, um desses velhos autos. Após os depoimentos, segue-se o despacho final da devassa, de 28 de agosto de 1782 e do teor seguinte: "Obrigam as testemunhas desta devassa a prisão e livramento a Bernardo e Gaspar, ambos escravos de Antonio José Dias, do bairro de Sant'Ana, pelo que o escrivão os ponha no ról dos culpados e passe as ordens devidas para serem presos"

Entretanto, a 27 de setembro, segundo consta do rosto dos autos de livramento-crime, a que está anexa dita devassa, "em audiência pública que dos feitos e partes e seus procuradores fazendo estava o juiz ordinário, o capitão Francisco Xavier dos Santos, em casa de sua morada" compareceu o procurador dos indiciados, Antonio da Costa Ferreira, com os escravos Bernardo e Gaspar "que se apresentavam com sua primeira carta de seguro confessativa com defesa pelo crime que lhe resultou da devassa tirada ex-oficio de Justiça pelo ferimento a João Pires da Silva, pardo forro, e assim requeria os houvesse por apresentados $e$ lhes mandasse passar seus contra-mandados para não serem presos"

4. E' que, sabedores da ordem de prisão contra eles expedida, os indiciados haviam se apressado em requerer ao corregedor, mesmo na ignorância do conteúdo probatório da devassa, ainda não aberta, a liberal garantia monárquica do seguro: 
“Dizem Bernardo e Gaspar, escravos de António Josẻ Dias, moradores no bairro de Sant'Ana, que a sua noticia veio que pessoas suas inimigas, $e$ de que não são sabedores, culparam e denunciaram aos suplicantes e principalmente fizeram em uma devassa que ex-oficio da Justiça tirou o Juiz Ordinário com fundamento de que os suplicantes deram umas pancadas, na vespera de S. João do presente ano, em João Pires, homem mulato e forro, sendo que esse foi o agressor daquela pendência por andar bebado. Como tambem os suplicantes e sem embargo de que andavam embriagados todo e qualquer excesso que obraram foi em sua natural defesa por serem os mesmos acometidos $e$ feridos, como assim o querem mostrar por meio de seu livramento; e por isso precisam os suplicantes de sua Carta de Seguro Confessativa com defesa, termos em que $P . V$ Mag. de lhes faça mercê mandar passar sua primeira Carta de Seguro Confessativa com defesa, para o caso recontado e Negativa para todos os mais de que lhes quizessem fazer culpa"

Fôra essa a medida preventiva dos reus contra a eventualidade de prisão processual.

A esse tempo, a Carta de Seguro Confessativa, que se concedia quando, ao requerê-la, o réu confessava o fato "debaixo de legítima defesa", como ensina Pereira e Sousa em suas "Primeiras Linhas sobre o Processo Criminal", tinha lugar nos casos das Ordenações L. 5, tit. 35 pr., tit. 38, tit. $127 \S 38$. A Carta de Seguro Negativa outorgava-se no caso do requerente negar o fato. Esse era o motivo legal por que Bernardo e Gaspar, em S. Paulo, em 1782, impetrando ao corregedor sua Carta de Seguro, pediam-na Confessativa quanto à agressão de que fôra vítima o pardo fôrro João Pires e Negativa para as imputações que ignoravam, acaso contidas na devassa.

Podiam requerê-la, porque o crime que se lhes atribuia não estava compreendido nas exceções legais que não admitiam Carta de Seguro; como morte, lesa-magestade, moeda 
falsa, defloramento, ferimento por arma proibida ou uso dela, crimes de Almotaceria, ou relativos ao govêrno da cidade, travessia de pão, sal ou palha, descaminhos de fazendas ou direitos de alfândega, crimes militares dos soldados, arrogar-se com certidões falsas fóros indevidos, ir a bordo de navios antes de descarregarem, recuar das carruagens. Além disso, no caso, não lhes havia ainda sido negada ou concedida a garantia nenhuma vez.

5. Houvera assim por bem o corregedor, dr. Sebastião José Ferreira Barroso, determinar, a 23 de setembro, a expedição do título requerido, cujo pitoresco convém conhecer:

"Dona Maria por graça de Deus Rainha de Portugal e dos Algarves daquem e aiem mar em Africa Senhora da Guiné e da conquista navegação comercio da Elhiopia Arabia, Persia e da India, etc..

A todos os meus Doutores Desembargadores Coregedores Provedores Ouvidores Julgaiores Juizes de Fóra com alçada Ordinários e Orfãos e Ministros de Justiça Officiais e mais pessôas della destes meus reinos e senhorios de Portugal e Estados do. Brasil e suas conquistas, agueles a quem e cada um dos quaes, ante e perante quem esta minha e mais verdacieira Carta de Seguro Primeira Confeçativa com defesa dada e passada em forma, virem $e$ o verdadeiro conhecimento de!a, em direito diretamente, deva logo pertenser, e o seu devido effeito inteiro, cumprimento e real execuçam da minha parte se pedir e requerer por qualquer via, modo, titulo, forma maneira razam ou de aumento que seja e ser possa a todos em geral e a cada hum em particular em suas jurisdiçoens e destritos. Faço saber que por parte dos suplicantes Bernardo e Gaspar escravos de Antonio José Dias do termo da minha Cidade de Sam Paulo me foi mandado escrever sua petisam retro o conteudo na mesma requerendo-me por concluzam da mesma lhes fizesse mercê concedendo sua primeira carta de Seguro Confesativa em defeza para os casos recontados na dita sua pitiçam a qual sendo -me assim feita fora outrosim apresentada ao meu Doutor Sebastiaó José Ferreira Barroco meu Ouvidor Geral e Corregedor da minha cidade e Co- 
marca de Sam Paulo a qual vendo-a e examinando-a nella proferira o seu despacho mandando se lhes passasse sua primeira carta de Seguro confesativa com defeza por hum anno pagos os novos direitos e por constar haver delles satisfeito duzentos rs. os quaes se carregaram em receita ao Thezoureiro do mesmos em observancia do dito despacho se lhes passou a presente que hindo assignada $e$ sellada com o sello das reaes armas que perante elle serve passando pela minha chancellaria e pagando nella o que deve na minha real fazenda de mais a cumpram e guardem façam mais inteiramente cumprir e guardar assim e da maneira que nella se contem e declara com seu cumprimento e por bem da mesma ley por bem e me pras segurar como com effeito hey por seguros aos Reos Bernardo e Gaspar escravos de Antonio José Dias por tempo de hum anno de todos os crimes e culpas expressos e declarados no requerimento retro e com estas se apresentaram perante as justigas a que tocar dentro do prefixo termo de desanove dias tomando se lhes sua apresentaçam por termos ao pé desta passando-se-lhes seos contra mandados para não serem prezos e faram citar a parte ou partes se as tiverem para declararem se os querem ou não acusar cuja citaçam será acuzada ficando esperados assignando-se-lhes os termos legaes sendo apregoados $\boldsymbol{e}$ nam comparecendo seram lansadas da accusaçam e de parte esta tomada pela minha justiça com a qual correram os termos de seo Livramento comparecendo em Juizo e fora delle seguramente sem que lhes seja feito mal algum rezidindo nas audiencias desde que fizerem citar as partes. se por a cauza em prova o qual Livramento será principiado findo e acabado dentro do termo de hum anno finajo o qual nam proseguirei mais nelle se mostrem certidam de prorogaçain de tempo pelo Tribunal da minha Relaçam respectiva e cumprindo os ditos Reos assim esta lhes será guardada e do contrario quebrado e ellesprezos na Cadea publica do lugar mais proximo a que se acharem do qual nam sahiram sem que primeiro se mostrem livres dos ditos crimes por sentença final o que assim cumprirei e al nam façais A Rainha Nossa Senhora o manda pelo Doutor Sebastian José Ferreira Barroco do seu Desembargo Ouvidor Geral e Carregedor com jurisdiçam e alçada no Civel e Crime nesta comarca de Sam Paulo tudo pela mesma Senhora que Deus guarde etc. 
Dada e passada nesta Cidade de Sam Paulo aos vinte e tres do mes de Setembro do Anno do Nascimento de Nosso Senhór Jezus Christo de mil e setecentos oitenta e dous = Pagou-se de feitio desta por parte dos Suplicantes, Bernardo e Gaspar que a pedirão e requereirão a quantia de seiscentos e quarenta réis de assignatura seis centos réis de sello, duzentos e de novos direitos e chancellaria duzentos e trinta réis e eu João da Costa e Sylva escrivão da Ouvidoria Geral e Corregedor q o escrevy, Sebam José Fr $^{a}$ Barroco"

6. Com esse documento, a 27 de setembro, se apresentaram os réus ao juiz ordinário, para se eximirem à prisão, requerendo "lhes mandasse passar seus contramandados" e que o escrivão "escrevesse carta ao dito João Pires da Silva pelo qual o citasse para vir à primeira audiência declarar" se quer ou não ser parte aos réus no seu livramento" O juiz deferiu-lhes todo o requerido e assim, soltos, iniciou-se o processo do livramento. Acham-se nos autos, pela ordem, dentre outros decumentos, a carta de seguro, lavrada ao pé do respetivo requerimento ao corregedor, folha corrida, termo de judiciais, procuração, citação do acusador particular, abertura e publicação da devassa, provas judiciais, razões finais e sentença. 